\title{
Visualisation and characterisation of mononuclear phagocytes in the chicken respiratory tract using CSF1R-transgenic chickens
}

\author{
Kate Sutton ${ }^{*}{ }^{\circledR}$, Taiana Costa $^{\dagger}$, Andreas Alber, Karen Bryson, Dominika Borowska, Adam Balic, Pete Kaiser ${ }^{\wedge}$, \\ Mark Stevens and Lonneke Vervelde
}

\begin{abstract}
The respiratory tract is a key organ for many avian pathogens as well as a major route for vaccination in the poultry industry. To improve immune responses after vaccination of chickens through increased uptake of vaccines and targeting to antigen presenting cells, a better understanding of the avian respiratory immune system is required. Transgenic MacReporter birds were used expressing a reporter gene (eGFP or mApple) under the control of the CSF1R promoter and enhancer in cells of the mononuclear phagocyte (MNP) lineage to visualize the ontogeny of the lymphoid tissue, macrophages and dendritic cells, in the trachea, lung and air sac of birds from embryonic day 18-63 weeks of age. Small aggregates of CSF1R-transgene ${ }^{+}$cells start to form at the openings of the secondary bronchi at 1 week of age, indicative of the early development of the organised bronchus-associated lymphoid tissue. Immunohistochemical staining revealed subpopulations of MNPs in the lung, based on expression of CSF1R-transgene, CD11, TIM4, LAMP1, and MHC II. Specialised epithelial cells or M cells covering the bronchus-associated lymphoid tissue expressed CSF1R-transgene and type II pneumocytes expressed LAMP1 suggesting that these epithelial cells are phagocytic and transcytose antigen. Highly organised lymphoid tissue was seen in trachea from 4 weeks onwards. Throughout the air sacs at all ages, CSF1R-transgene ${ }^{+}$cells were scattered and at later stages, CSF1R-transgene ${ }^{+}$cells lined capillaries. These results will serve as a base for further functional characterization of macrophages and dendritic cells and their role in respiratory diseases and vaccine responses.
\end{abstract}

\section{Introduction}

In the poultry industry, vaccines are frequently delivered via spray and aerosol, providing an economical, efficient and reliable method for immunisation of a large number of birds. The respiratory tract is a major portal of entry of pathogens that are of economic or zoonotic importance, such as avian influenza virus (AIV), infectious bronchitis virus (IBV), Newcastle Disease virus and avian pathogenic Escherichia coli (APEC). Surprisingly little is known

\footnotetext{
*Correspondence: kate.sutton@roslin.ed.ac.uk

${ }^{\dagger}$ Kate Sutton and Taiana Costa contributed equally to this work

${ }^{\wedge}$ Pete Kaiser-Deceased

Division of Infection and Immunity, The Roslin Institute and Royal (Dick),

School of Veterinary Studies, University of Edinburgh, Easter Bush,

Midlothian EH25 9RG, UK
}

about the ontogeny and function of the immune cells in the avian respiratory tract. Similar to mammals, nonspecific defense mechanisms, such as aerodynamic filtration, mucociliary clearance and antimicrobial substances are the first line of defense of the avian respiratory tract [13]. The avian respiratory system differs significantly from mammals. For example, birds have relatively rigid lungs, lack a diaphragm and the lung opens into 9 air sacs that function as bellows, with a unidirectional air flow pattern that affects the deposition of particles [4-6].

The lymphoid tissue in the avian lung can be divided into highly organized lymphoid structures such as the bronchus-associated lymphoid tissue (BALT) and diffusely distributed lymphoid cells in the lamina propria around secondary bronchi and in the parabronchi and

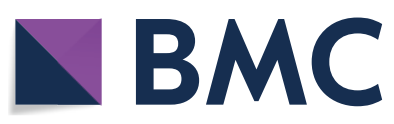

c The Author(s) 2018. This article is distributed under the terms of the Creative Commons Attribution 4.0 International License (http://creativecommons.org/licenses/by/4.0/), which permits unrestricted use, distribution, and reproduction in any medium, provided you give appropriate credit to the original author(s) and the source, provide a link to the Creative Commons license, and indicate if changes were made. The Creative Commons Public Domain Dedication waiver (http://creativecommons.org/ publicdomain/zero/1.0/) applies to the data made available in this article, unless otherwise stated. 
the interparabronchial connective tissue. In chickens, BALT structures are confined to the openings of the most caudal secondary bronchi (SB) [7], the laterodorsal SB and the posterior SB [8] (Figure 1). Mature BALT structures consist of a distinctive layer of epithelial cells, the lymphoepithelium or follicle-associated epithelium (FAE) [9] overlying primary follicles with densely packed lymphocytes and secondary follicles with germinal centers (GCs) with a subepithelial dome consisting of $\mathrm{CD}^{+} \mathrm{T}$ cells, similar to Peyer's patches and other gut-associated lymphoid tissue (GALT) [10]. $\mathrm{CD}^{+} \mathrm{T}$ cells and heterophils are distributed throughout the BALT [1]. BALT appear as early as $2-3$ weeks of age and its development is influenced by age and environmental stimuli $[7,11]$.

To rapidly detect invading pathogens, the respiratory tract is lined with monocytes, macrophages and dendritic cells (DCs), collectively termed mononuclear phagocytes (MNP). Macrophages maintain a low inflammatory environment in the lung, as the infiltration of cells in response to inflammatory stimuli reduces the efficiency of gas exchange, but during infection they immediately induce a response in coordination with epithelial cells and DCs [reviewed in [12,13]. Polynuclear phagocytes, or granulocytes, and type II pneumocytes (also known as type II alveolar epithelial cells) also display phagocytic capacity, but these cells have distinct functions compared to MNPs. In the mammalian lung during steady state, distinct populations of alveolar macrophages, interstitial macrophages and DCs have been described based on multicolour flowcytometry, but during inflammation this distinction becomes less straight forward [reviewed in 12,13$]$. In contrast to mammals, the chicken lung contains very few free-residing macrophages comparable to alveolar macrophages [14]. However, many cells express macrophage and DC markers and are scattered throughout the interstitial tissue of the parabronchial wall and in close contact to the epithelium [15-17]. These cells are expected to play a similar role as mammalian alveolar macrophages and seem to be strategically located at the start of the gas-exchange area to clear the air of inhaled particles before it reaches the thin and vulnerable air capillaries [17].

The trachea in steady state is lined by ciliated pseudostratified columnar epithelium and has a relatively thin lamina propria with large numbers of mucous glands. The ciliated epithelium and mucus create a mucociliary escalator which forms an essential mechanism for entrapment and clearance of particulate material. The lamina propria leukocytes consist mainly of macrophages and an occasional $\mathrm{CD} 4^{+}$and $\mathrm{CD} 8^{+} \mathrm{T}$ cells and B cells [18]. After infection with respiratory pathogens, such as IBV, E. coli or AIV, the tracheal wall thickens and large infiltrations of macrophages and $\mathrm{T}$ cells have been described [19-21].

Little is known about the immune cells that reside within the air sacs, partly owing to their fragility and the low number of cells that can be extracted for ex vivo analysis $[19,22]$. The respiratory surface of the air sacs is lined by a simple epithelium, either flat or ciliated, on a basement membrane supported by a thin layer of connective tissue $[22,23]$ where scattered solitary phagocytes have been reported [24]. The lamina propria of the air sacs contains small capillaries [25], arterioles, venules and lymph vessels [23]. Small lymphoid aggregates have occasionally been seen in the epithelium of the air sacs [11], and they increase in size and number upon infection [22].

The development of transgenic chickens, such as the CSF1R-transgenic or MacReporter chicken, enables visualization of the immune system as the reporter gene expression gives a unique macroscopic view of chicken lymphoid structures [26]. CSF1R-transgenic chickens express the gene for a fluorescent protein under the

\section{Caudal}

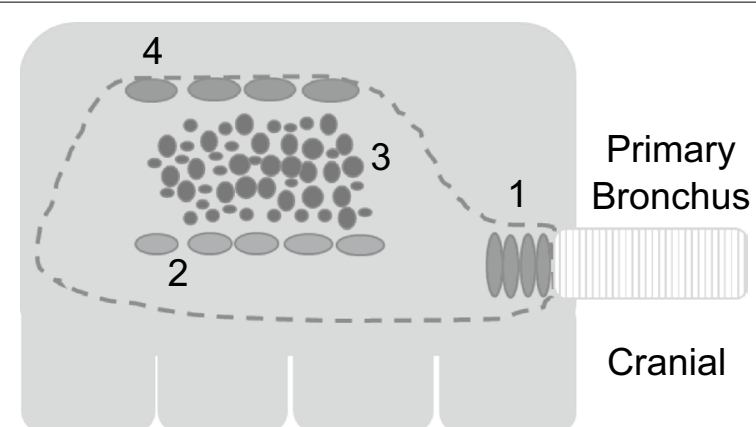

Figure 1 Schematic overview of the anatomy of the lung. Frontal plane of the right lung showing the extrapulmonary primary bronchus enters the lung and branches out to secondary bronchi and openings of the medioventral (1), laterodorsal (2), posterior secondary (3), and lateroventral (4) secondary bronchi are depicted (based on Makanya and Djonov [8]). From the secondary bronchi a large number of tertiary bronchi or parabronchi originate. 
control of the CSF1R promoter and enhancer, in many hematopoietic cells of the monocyte lineage and at low levels in heterophils [26]. Transgene expression is not a definite marker for all MNP in the chicken as it was recently shown that the Kupffer cells in the liver of MacReporter chickens lack transgene expression, but express CSF1R mRNA, indicating an alternative control of CSF1R expression [27]. In this study, we first investigated the ontogeny of the MNPs in the chicken respiratory tract from embryonic day (ED) 18 up to adult birds, and phenotypically characterized cell subpopulations in situ. These transgenic birds enable future studies on the interaction between MNPs and respiratory pathogens, antigen uptake and mucosal targeting of respiratory vaccines.

\section{Materials and methods \\ Chicken lines}

Two transgenic chicken lines, collectively named MacReporter chickens, were used in this study. MacRed birds express a modified red fluorescent protein (mApple) and MacGreen birds express an enhanced green fluorescent protein (eGFP) in cells of the mononuclear phagocyte lineage, under the control of the CSF1R promoter and enhancer [26]. Birds were bred and reared in floor pens at the National Avian Research Facility, The Roslin Institute, Edinburgh (UK). The animals used for developmental studies and whole mount imaging were vaccinated according to Additional file 1. Animals used for immunohistology were not vaccinated. The chickens were housed in groups and received food and water ad libitum. All birds were considered healthy by physical examination. The age groups studied included MacRed birds at ED18, 1 day, and 1, 2, 4, 8, 10, 16, 30 and 40 weeks of age, and MacGreen birds at 5, 7, 11 and 63 weeks of age (not all ages shown) and were of mixed sexes. Four to six individuals per age group were randomly selected and killed by cervical dislocation, and death was confirmed by decapitation. Animals were housed in premises licensed under a UK Home Office Establishment License (PEL 60/4604) in full compliance with the requirements of the Animals (Scientific Procedures) Act 1986. Breeding of transgenic chickens was carried out under the authority of Project License PPL 70/8940 and application of substances was conducted under PPL 70/7860 with the consent of The Roslin Institute Animal Welfare and Ethical Review Board.

\section{Tissue preparation}

Tissues were collected immediately after death using standard avian necropsy techniques. Both lungs containing the primary bronchi were carefully removed from the coelomic cavity. One of the lungs was incised longitudinally on its ventral aspect, from the extrapulmonary primary bronchus into the intrapulmonary primary bronchus, in order to enable imaging the mucosa of the intrapulmonary primary bronchus and the openings to the SB. The other lung was incised transversally along the second costal sulci. The trachea, from the first tracheal rings to just above the carina, was dissected from the cervical area and two parallel longitudinal incisions were made to expose the tracheal mucosa. The cranial and caudal thoracic air sacs were collected intact and flat using the card-collection technique (Whatman ${ }^{\circledR}$, Grade 54) [28]. After dissection, tissues were kept in a Petri dish on ice, and whole mount fluorescence imaging was immediately performed. Whole mount tissues were evaluated for the presence of fluorescence using the AXIO Zoom.V16 fluorescence stereo zoom microscope (Carl Zeiss Zen pro 2012 software).

\section{Immunofluorescence}

Tissues were fixed in $4 \%$ paraformaldehyde for 3-6 $\mathrm{h}$ at $4{ }^{\circ} \mathrm{C}$, gently rinsed in phosphate buffered saline (PBS), and overnight immersed in $30 \%$ sucrose at $4{ }^{\circ} \mathrm{C}$. Tissue samples were snap frozen in liquid nitrogen and stored at $-80{ }^{\circ} \mathrm{C}$ until use. Samples were sectioned at $7 \mu \mathrm{m}$ onto Superfrost Plus slides, air dried in the dark at room temperature (RT) for at least $2-24 \mathrm{~h}$ before staining. Sections were blocked for $1 \mathrm{~h}$ using 2.5\% Skim Milk Powder (SMP, Oxoid), 1\% Triton X-100 (Sigma), and 10\% normal goat serum or $10 \%$ normal horse serum (AMS Biotechnology) in PBS (blocking buffer). All sections were incubated with the primary antibody diluted in blocking buffer at $4{ }^{\circ} \mathrm{C}$ overnight and washed in PBS, followed by incubation with the appropriate secondary antibody diluted in blocking buffer and $10 \mu \mathrm{g} / \mathrm{mL}$ of $4^{\prime}, 6$-diamidino-2-phenylindole (DAPI; Sigma-Aldrich) for $2 \mathrm{~h}$ at RT and washed in PBS. The primary and secondary antibodies used for cell-specific staining are listed in Table 1. Sections were mounted using SlowFade ${ }^{\circledR}$ Gold or using ProLong ${ }^{\circledR}$ Diamond Antifade Mountant (Life Technologies; ThermoFisher Scientific). In each study involving immunofluorescence staining, a tissue section from a chicken that does not express the CSF1R-transgene was included as an auto-fluorescence control, and one extra tissue section from the transgenic bird was included and incubated with an unrelated antibody of the same isotype and concentration as the primary antibody as an isotype control for aspecific staining and calibration of the microscopes (see Additional file 2). Images were captured using a Leica DMLB fluorescence microscope (Micro-Manager 1.4.18 software) and confocal images were obtained using an inverted confocal microscope (Zeiss LSM710) and captured using Zeiss Zen (Black) 2012 software. 
Table 1 List of primary and secondary antibodies used for immunohistochemistry

\begin{tabular}{|c|c|c|c|c|}
\hline Antibody name & Antigen & Isotype & Supplier & $\begin{array}{l}\text { Working } \\
\text { concentration }\end{array}$ \\
\hline Rabbit anti-GFP Alexa Fluor ${ }^{\circledR} 488$ & eGFP transgene & $\lg G$ & Thermo Fischer Scientific & $4 \mu \mathrm{g} / \mathrm{mL}$ \\
\hline Mouse anti-chicken MHCII (clone TAP1) & Class II MHC & $\lg G 2 a$ & DSHB & $0.2 \mu \mathrm{g} / \mathrm{mL}$ \\
\hline Mouse anti-chicken CD11 (clone 8F2) & CD11 & $\lg G 1$ & Kind gift from Dr Sonja Hartle (LMU) & $3 \mu \mathrm{g} / \mathrm{mL}$ \\
\hline Mouse anti-chicken TIM4 (clone JH9) & TIM4 & $\lg G 1$ & In house [27] & $2 \mu \mathrm{g} / \mathrm{mL}$ \\
\hline Mouse anti-chicken LEP100 & $\begin{array}{l}\text { Chicken lysosomal-associated membrane } \\
\text { glycoprotein (LAMP1), present in late } \\
\text { endosome and lysosomes }\end{array}$ & $\lg G 1$ & DSHB & $10 \mu \mathrm{g} / \mathrm{mL}$ \\
\hline Mouse anti-chicken lgG (clone G-1) & $\lg Y$ & $\lg G 1$ & Southern biotech & $5 \mu \mathrm{g} / \mathrm{mL}$ \\
\hline Mouse anti-chicken Bu-1 (clone AV20) & chB6 & $\lg G 1$ & Southern biotech & $5 \mu \mathrm{g} / \mathrm{mL}$ \\
\hline Mouse anti-chicken CD3 (clone CT3) & CD3 & $\lg G 1$ & Southern biotech & $5 \mu \mathrm{g} / \mathrm{mL}$ \\
\hline Jacalin-biotin & O-glycosidically linked oligosaccharides & - & Vector Laboratories & $10 \mu \mathrm{g} / \mathrm{mL}$ \\
\hline Phalloidin-Alexa Fluor ${ }^{\circledR} 647$ & F-actin & - & Thermo Fischer Scientific & $0.132 \mu \mathrm{m}$ \\
\hline Mouse lgG1 (NC-1390-P) & $\operatorname{lgG} 1$ isotype & $\lg G 1$ & Thermo Fischer Scientific & $5 \mu \mathrm{g} / \mathrm{mL}$ \\
\hline Mouse lgG2a (NC-1391-P) & lgG2a isotype & $\lg G 2 a$ & Thermo Fischer Scientific & $5 \mu \mathrm{g} / \mathrm{mL}$ \\
\hline Donkey anti-rabbit lgG Alexa Fluor 488 & Rabbit lgG & $\lg G$ & Invitrogen & $2 \mu \mathrm{g} / \mathrm{mL}$ \\
\hline Goat anti-mouse lgG1 Alexa Fluor ${ }^{\circledR} 568$ & Mouse $\operatorname{lgG} 1$ & $\operatorname{lgG} 1$ & Invitrogen & $2 \mu \mathrm{g} / \mathrm{mL}$ \\
\hline Goat anti-mouse IgG2a Alexa Fluor ${ }^{\circledR} 568$ & Mouse lgG2a & $\lg G 2 a$ & Invitrogen & $2 \mu \mathrm{g} / \mathrm{mL}$ \\
\hline Streptavidin- Alexa Fluor ${ }^{\circledR} 568$ & Biotin & - & Biolegend & $0.2 \mu \mathrm{g} / \mathrm{mL}$ \\
\hline
\end{tabular}

DSHB: Developmental Studies Hybridoma Bank; LMU: Ludwig-Maximilian University, Munich, Germany.

\section{Uptake of antigens}

Three-week-old MacGreen birds were administered 0.1 or $1 \mu \mathrm{m}$ Yellow/Green FluoSpheres ${ }^{\mathrm{TM}}$ Carboxylate-Modified Microspheres (Thermofisher) intratracheally using a flexible oral gavage needle $(20 \times 38 \mathrm{~mm}$, Instech). Alternatively, MacRed animals were administered heat-inactivated APEC engineered to express GFP intratracheally using a flexible oral gavage needle $(20 \times 38 \mathrm{~mm}$, Instech). The genome sequenced APEC 01 strain (serotype O1:K1:H7 [29]) was transformed with plasmid pFVP25.1 [30] for this purpose. Samples were collected for whole mount and immunofluorescence analysis $30 \mathrm{~min}, 3 \mathrm{~h}$ and 1 day post-administration as previously outlined.

\section{Results}

Development and distribution of mononuclear phagocytes and germinal centers in the lung of CSF1R-transgenic birds The distribution of CSF1R-transgene expressing cells was examined in lungs of MacReporter birds of different ages by whole mount microscopy. These birds were reared in floor pens on wood shavings and routinely vaccinated, albeit via non-respiratory routes (Additional file 1). Therefore, the lymphoid accumulations observed are in part in response to environmental particles and the vaccinations. Although BALT development follows a similar time course in specific pathogen-free and conventionally reared chickens, differences were observed with regard to germinal center (GC) development [7].
In the lung scattered individual CSF1R-transgene ${ }^{+}$ cells were distributed over the entire mucosa of the intrapulmonary primary bronchi in all age groups (Figures $2 \mathrm{~A}-\mathrm{L}$ ). At ED18 and 1 day of age, there are no signs of organised structures or cellular aggregates of CSF1Rtransgene $^{+}$cells (Figures $2 \mathrm{~A}$ and B). Small aggregations of CSF1R-transgene ${ }^{+}$cells were first observed at 1 week of age (Figure $2 \mathrm{C}$ ). They are primarily located at the vicinity of openings of laterodorsal and mediodorsal SB. With increasing age these aggregates become larger and more numerous (Figures 2D-J). They are distributed at the vicinity of the laterodorsal, mediodorsal and medioventral openings. From 4 weeks of age onwards, GCs are observed within these lymphoid follicles, and they are characterized by tightly packed aggregates of CSF1Rtransgene $^{+}$cells (Figures $2 \mathrm{E}-\mathrm{H}$ ). GCs in older birds are larger with some lymphoid follicles containing several GCs (Figures 2I and J), similar to the Peyer's patches of the small intestine [1]. Lymphoid follicles residing in the BALT region were occasionally observed in the vicinity of the third and fourth openings of the medioventral SB, and follicles were also present in the vicinity of the openings of the medioventral SB.

In this study, the lateroventral SB were not appreciated, as they do not open directly into the intrapulmonary primary bronchi and are unlikely to be identified using non-casting methods [8]. Moreover, organised lymphoid tissue with and without GCs were observed on the transversal sections of the SB within the parabronchi, 

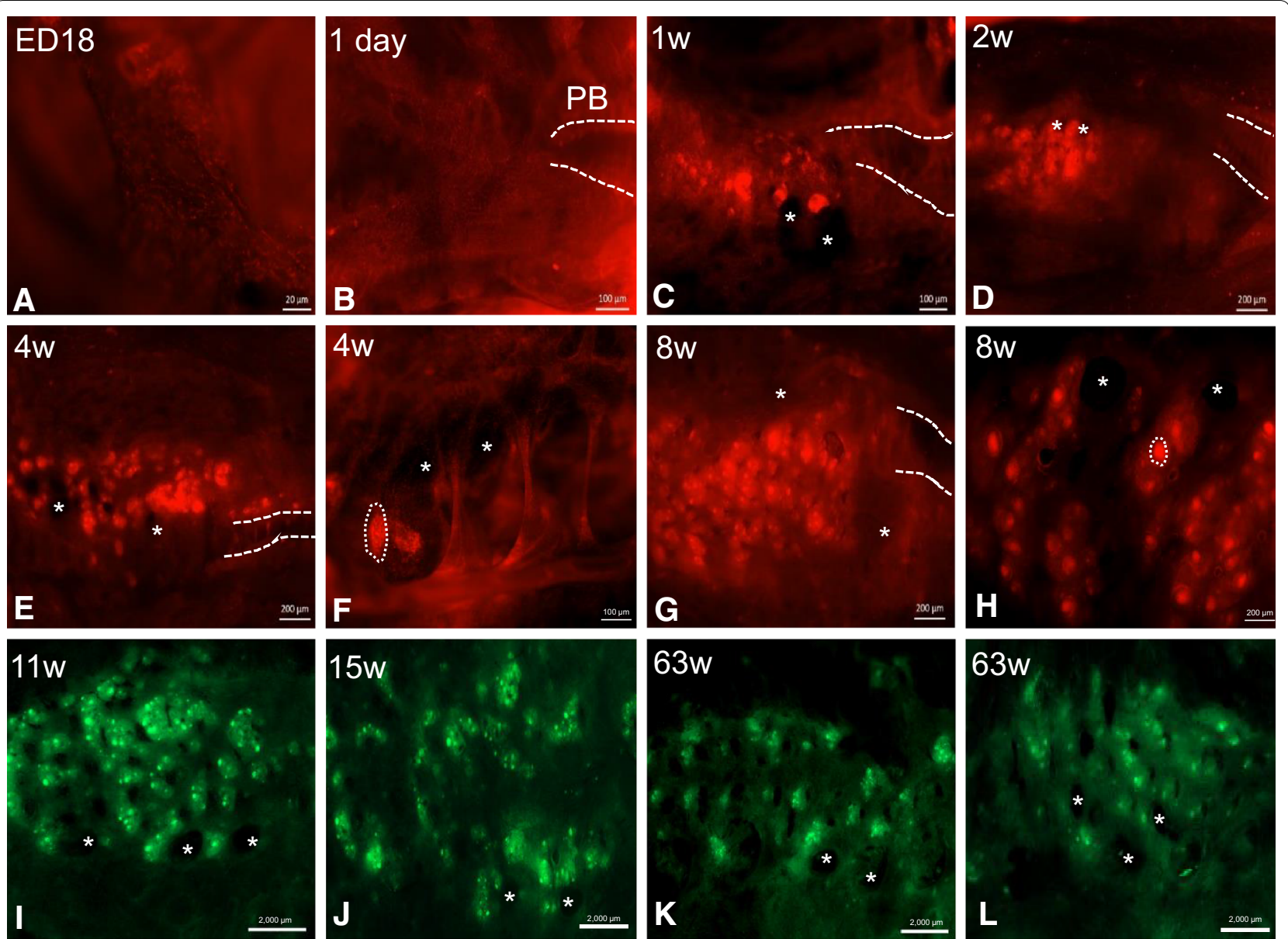

Figure 2 Development of BALT regions in the intrapulmonary primary and secondary bronchi of CSF1R-transgenic birds. Whole mount analysis of the intrapulmonary bronchi of a CSF1R-mApple chicken. BALT structures are associated with each opening of the secondary bronchi and increase in size and number with age (A-L). Intrapulmonary bronchi of older CSF1R-eGFP animals show the presence of BALT (K-L) and the number of lymphoid follicles seemingly reduces in older animals (K-L). Primary bronchus (PB) is indicated by dashed lines, lymphoid follicles indicated by a dashed circle and openings to the secondary bronchi are marked by an asterisk. $\mathrm{W}=$ week/s of age.

indicating that they are not restricted to the openings of the medioventral SB as it enters the parabronchial tissue. The animals used in this study appeared to have BALT structures 1 week post-hatch which were present in birds of up to 63 weeks of age, although the number of follicles seems reduced in older animals this could be attributed to the increase in lung size and follicles being dispersed over a larger surface area (Figures $2 \mathrm{~K}$ and L).

\section{Immunofluorescent staining of cell populations} in the bronchus-associated lymphoid tissue

To enable a more in-depth phenotypical analysis of MNP subpopulations, immunostaining of BALT and parabronchi was performed on non-vaccinated animals between 5 and 7 weeks of age. CSF1R-transgene ${ }^{+}$cells were abundantly present in BALT structures and were more tightly packed in the centers or light zone of GCs than in other parts of the lymphoid tissue (Figures 3A and B). This is consistent with previous reports of monocytes/macrophages and DC type cells present in the BALT, which are CVI-ChNL-68.1 and CVI-ChNL-74.2-positive, and express $\mathrm{MHC}$ II $[1,31] . \mathrm{chB}^{+} \mathrm{B}$ cells were found to be tightly packed in GCs interspersed with CSF1Rtransgene $^{+}$cells, while $\mathrm{CD}^{+} \mathrm{T}$ cells were observed to aggregate in poorly demarcated areas within the BALT, in the subepithelial areas and in between GCs (Additional file 2). The remaining areas of the BALT have a more disperse population of both $B$ and T cells (Additional file 2).

GCs have tightly packed CSF1R-transgene ${ }^{+}$cells (Figures 3A and B) known as follicular dendritic cells (FDC) that express CD11, but not MHC II (Figures 3C and D) and have previously shown to express CVI-ChNL-74.3 [31]. FDCs are characterised by trapping immune complexes via Fc receptors (Additional file 2). Their enzyme content is restricted to non-specific esterase and adenosine triphosphate $[32,33]$. FDCs are absent in the dark 

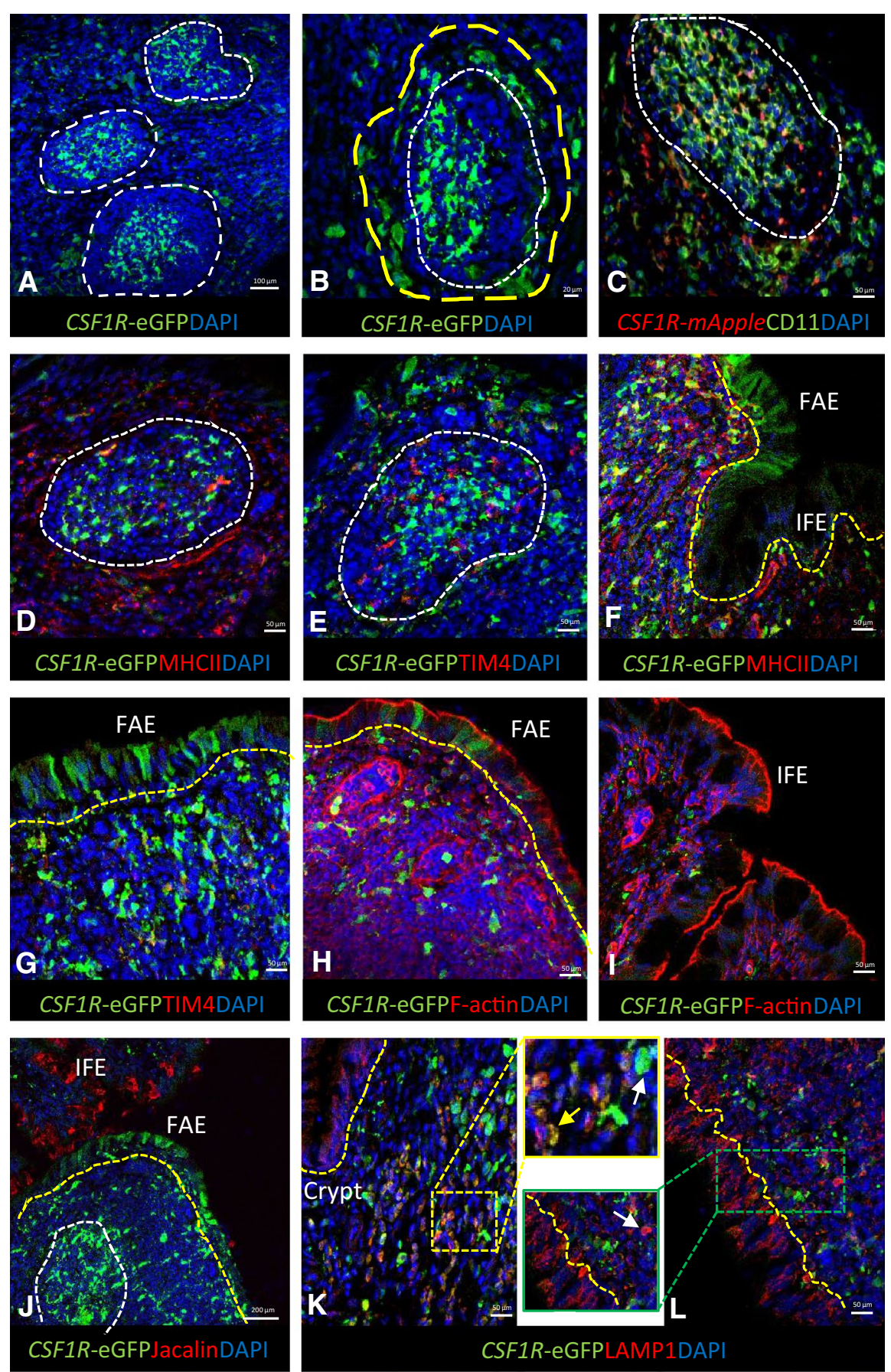

Figure 3 The BALT region in CSF1R-transgenic birds. The BALT of the chicken lung is constitutive, consisting of several GC (A) with tightly packed CSF1R-eGFP ${ }^{+}$cells in the light zone and a characteristic halo of MPN surrounding the GC (B). In the GC, CSF1R-transgene ${ }^{+}$cells express CD11 (C) and lack MHC II (D). TIM4 ${ }^{+}$CSF1R-transgene ${ }^{-}$cells are present in the GC known as tingible body macrophages. Outside the GC occasional $\mathrm{TIM}^{+}$CSF1R-transgene ${ }^{+}$cells were observed (E). CSF1R-eGFP+ cells can be found in regions of the epithelial overlaying the BALT (FAE), called M cells $(\mathbf{F}-\mathbf{H})$. Lung M cells lack MHC II (F) and TIM4 (G) expression. The M cells express high levels of F-actin (H) similar to IFE cells (I). M cells lack jacalin

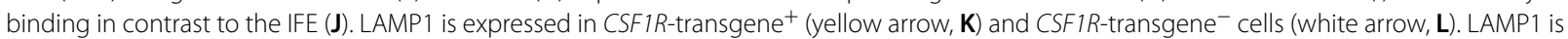
also highly expressed by epithelial cells (L). GC are indicated by white dashed lines with halo of cells identified with a yellow dashed circle, epithelial layer is indicated by yellow dashed lines. 
zone or periphery of a GC where the rate of B cell proliferation is high [34]. We observed a large population of $\mathrm{CD}_{11^{+}}$cells to be present throughout the BALT. In GCs, $\mathrm{CD}_{1}{ }^{+}$cells were tightly packed, and virtually all CSF1R-transgene ${ }^{+}$cells were $C D 11^{+}$. While most of the CSF1R-transgene ${ }^{+}$cells are $\mathrm{CD} 11^{+}$, small subpopulations of CSF1R-transgene ${ }^{-} \mathrm{CD}_{1} 1^{+}$and occasional CSF1Rtransgene ${ }^{+} \mathrm{CD} 11^{-}$cells were observed outside the GCs (Figure 3C).

In addition, GCs contain a cell population with remnants of nuclei in their cytoplasm, also known as starrysky or tingible body macrophages. In the chicken, these cells express TIM4, a receptor for phosphatidylserine, and engulf apoptotic cells. These TIM4 ${ }^{+}$cells lack transgene expression (Figure 3E), but possibly express CSF1R transcript as previously described for TIM4 ${ }^{+}$ CSF1R-transgene ${ }^{-}$cells in the chicken spleen [27].

The epithelium overlying the BALT consist of the follicle-associated epithelium (FAE) and interfollicular epithelium (IFE). Occasionally, in the FAE, CSF1R-transgene ${ }^{+}$ cells were observed that were negative for common APC markers used in this study (Figures $3 \mathrm{~F}$ and G). These cells likely represent airway $M$ cells whose primary function is to transport mucosal particles to underlying APCs [35, 36] and have recently been described in the avian bursa (Balic \& Vervelde, unpublished observations). The FAE and IFE highly express F-actin at the apical side of the cell which likely plays a role in remodeling of the cells during endocytosis (Figures $3 \mathrm{H}$ and I) [37]. Differentiation between FAE and bronchial IFE was visualised with the $\alpha$-D-galactose binding lectin, jacalin. Jacalin does not bind to the FAE, but binds to bronchial IFE cells (Figure 3J), suggesting that the FAE covering the BALT, similar to the epithelium covering the gut-associated lymphoid tissue or Peyer's patches, differs in detail in relation to their function.

Staining of lysosome-associated membrane glycoprotein-1 (LAMP1/CD107a) was cytoplasmic and granular and correlated with the location of lysosomes, organelles that degrade intracellular material endocytosed by the cell. Scattered LAMP1 ${ }^{+}$cells were found to be distributed within the BALT, and non-GC areas (Figures $3 \mathrm{~K}$ and $\mathrm{L}$ ). Almost all $\mathrm{LAMP}^{+}$cells express the CSF1R-transgene, with occasional cells being LAMP1 ${ }^{+}$ CSF1R-transgene ${ }^{-}$(Figures $3 \mathrm{~K}$ and L). LAMP1 was also found to be highly expressed by epithelial cells of the BALT (Figure 3L).

\section{Immunofluorescent staining of cell populations in the parabronchi}

Similar to the BALT, non-vaccinated 5-7 week old animals were used to study cells in the parabronchi in more detail. Scattered CSF1R-transgene ${ }^{+}$cells are present throughout the parabronchi, including in the infundibulum and interatrial septa and occasionally observed in the epithelium of parabronchi, around atrial smooth muscle (Figure 4). B and T lymphocytes are scattered throughout the parabronchi with $\mathrm{T}$ cells found to be in close proximity with CSF1R-transgene ${ }^{+}$cells (Additional file 2 ).

More in depth analysis of the MNP subpopulations shows scattered $\mathrm{CD}_{1} 1^{+}$cells present throughout the parabronchi, including interatrial septa (Figures 4A and D). All CSF1R-transgene ${ }^{+}$cell expressed CD11 and a subpopulation of $\mathrm{CD} 11^{+}$cells were observed to be CSF1Rtransgene ${ }^{-}$. Clusters of $\mathrm{CD}_{1} 1^{+}$CSF1R-transgene ${ }^{-}$cells were also observed in association with blood vessels in the connective tissue that separates two adjoining parabronchial lobules. Individual $\mathrm{MHC} \mathrm{II}^{+}$cells were found to be distributed throughout the parabronchi, including in the atrial septa (Figures 4B and E). Most of the MHC $\mathrm{II}^{+}$cells are also CSF1R-transgene ${ }^{+}$, with some scattered $\mathrm{MHC} \mathrm{II}^{+}$CSF1R-transgene ${ }^{-}$cells in the lamina propria, likely being $B$ cells.

Furthermore, we observed perivascular lymphoid aggregates of $\mathrm{CD} 11^{+}$cells in the parabronchi which have previously been reported [11]. Occasionally, MHC $\mathrm{II}^{+}$ cells formed small aggregates and are likely DCs and B cells. The antibodies used in this study do not suffice to distinguish between macrophages and DCs because both cell populations can express the CSF1R-transgene, MHC II, CD11, and LAMP1.

A majority of the CSF1R-transgene ${ }^{+}$cells expressed LAMP1 and these cells were located in the atrial septa and infundibulum. Pneumocytes in the interatrial septa were CSF1R-transgene ${ }^{-}$but strongly positive for LAMP1, in contrast, epithelium lining the infundibula and air capillaries were negative for LAMP1 (Figures 4C and F).

\section{Development and distribution of MNP and GCs in the trachea of CSF1R-transgenic chickens}

The distribution of CSF1R-transgene expressing cells was examined in trachea of MacReporter chickens of different ages. Scattered individual CSF1R-transgene ${ }^{+}$ cells were observed to be distributed throughout the tracheal mucosa, in all age groups (Figures 5A-E). At ED18 the formation of tracheal epithelium is evident and becomes more defined 1 day post-hatch (Figures $5 \mathrm{~A}$ and $\mathrm{B}$ ). Although rarely observed at 1 day of age, small aggregates of CSF1R-transgene ${ }^{+}$cells were observed throughout the trachea at 1-week of age (Figure 5C). These lymphoid aggregates increase in size and number as the bird increases in age (Figures $5 \mathrm{D}$ and $\mathrm{E}$ ). From 4 weeks onwards, areas with multiple lymphoid follicles were observed on the 

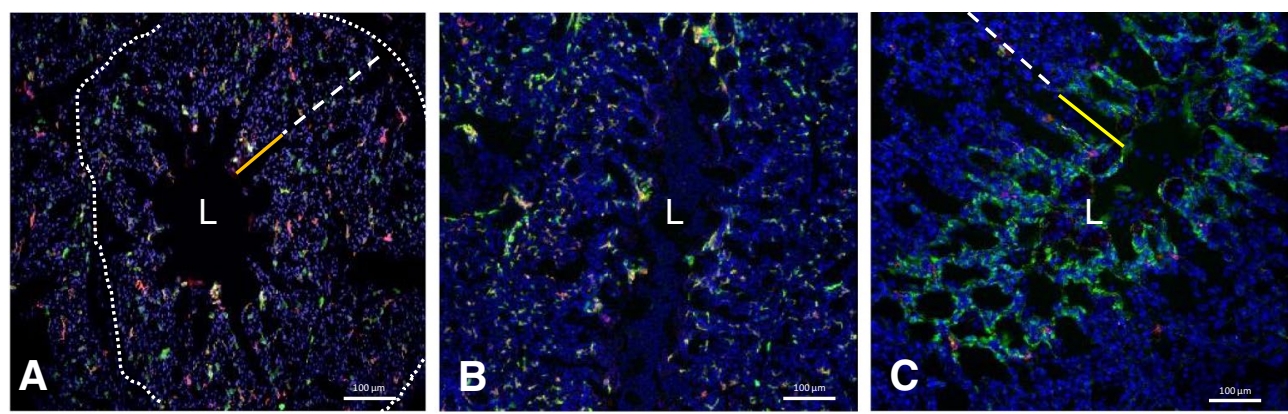

CSF1R-mAppleCD11DAPI

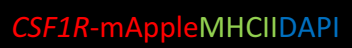

\section{CSF1R-mAppleLAMP1DAPI}
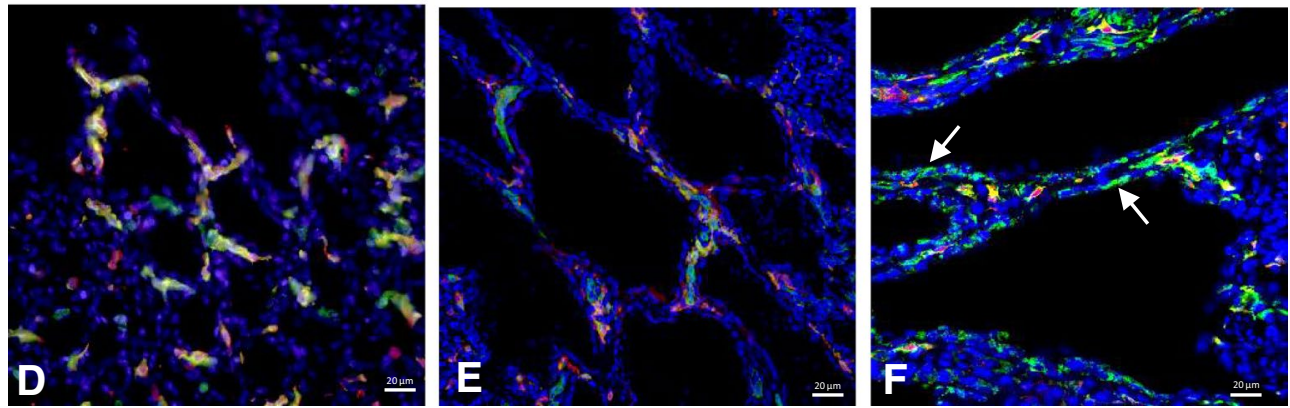

Figure 4 The parabronchus region in CSF1R-transgenic birds. Tertiary bronchi or parabronchi represent the functional unit of gas exchange and consist of a lumen (L), atria (solid yellow line) and infundibulum (dashed white line) surrounded by connective tissue that contains blood vessels and lymphoid follicles (indicated by dotted line). Scattered CSF1R-transgene ${ }^{+}$are located throughout the parabronchus and co-express CD11 (A) and MHC II (B). LAMP1 is expressed in the majority of the CSF1R-transgene ${ }^{+}$cells and in the pneumocytes in the interatrial septa (C). Enlargements of the interatrial septa (D-F).

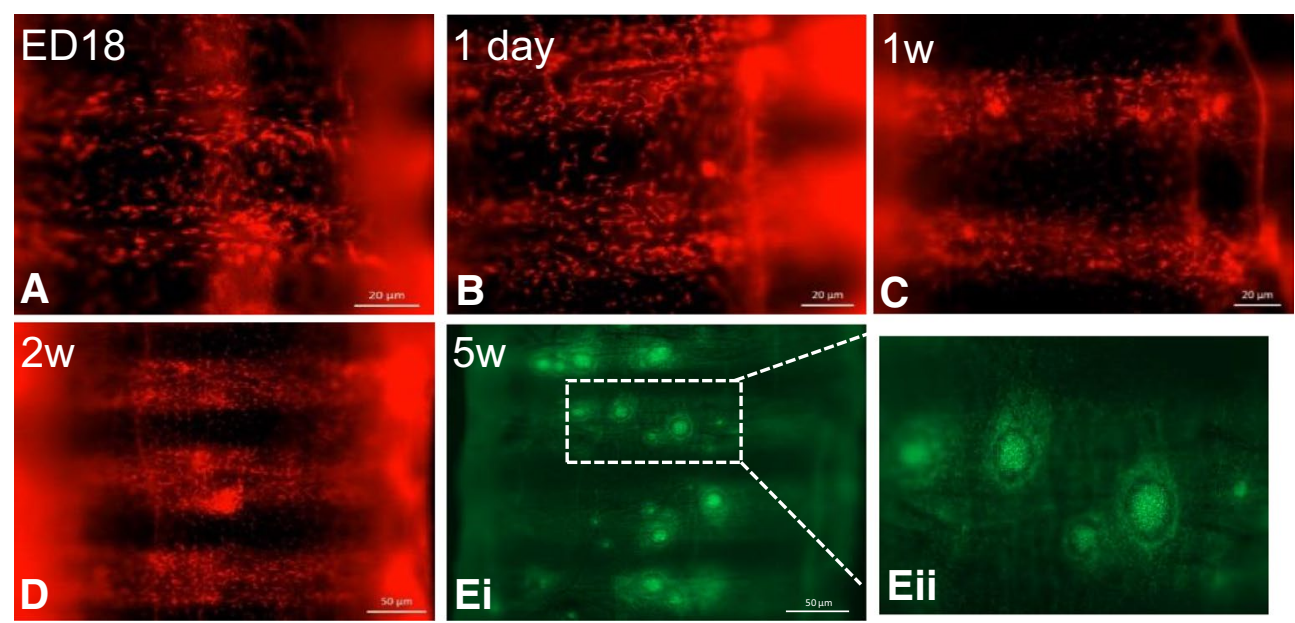

Figure 5 Development and distribution of MNP and GCs in the trachea of CSF1R-transgenic birds. CSF1R-mApple ${ }^{+}$cells are distributed throughout the tracheal mucosa from ED18, forming small aggregates from 1 week of age (A-D). At 5 weeks post-hatch, mature GC with tightly packed CSF1R-eGFP ${ }^{+}$cells are surrounded by a halo of CSF1R-transgene ${ }^{+}$cells (Ei-Eii). w $=$week/s of age.

tracheal mucosa, containing tightly packed CSF1Rtransgene $^{+}$cells and a clear halo, which become larger and more numerous as the bird ages (Figure 5E). Scattered individual CSF1R-transgene ${ }^{+}$cells were abundantly present in tracheal lamina propria (Figure 5).

\section{Development and distribution of MNP and GCs in air sacs} of CSF1R-transgenic chickens

The distribution of CSF1R-transgene expressing cells was examined in the air sac of MacReporter chickens of different ages (Figure 6). Scattered individual 

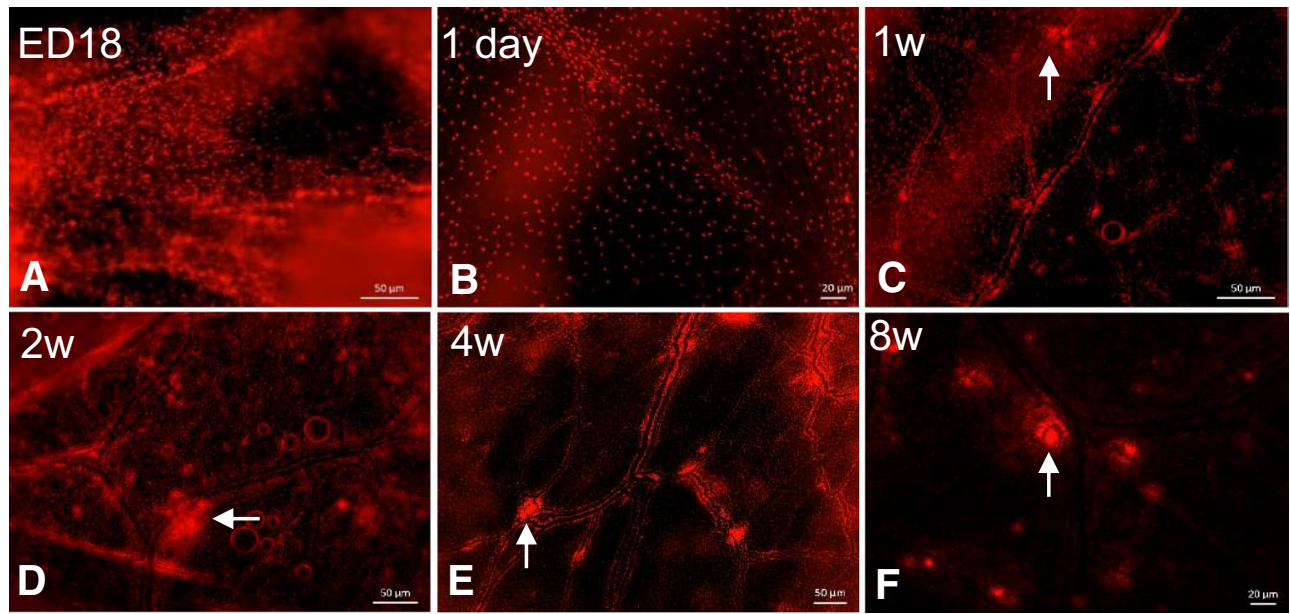

Figure 6 The development of MNP and GC in air sacs of CSF1R-transgenic birds. Whole mount images show that CSF1R-mApple ${ }^{+}$cells are distributed throughout the air sac on ED18 (A) and begin to form a pattern 1 day post-hatch (B). By 1-2 weeks of age the air sacs have developed an organised distribution that consist of MNP lining the vessels and early lymphoid aggregate formations at the bifurcations of the capillaries (arrows C, D). By 4 weeks of age these lymphoid aggregates have developed into characteristic GC (arrows $\mathbf{E}, \mathbf{F}$ ). W= week/s of age.

CSF1R-transgene ${ }^{+}$cells were distributed throughout the air sacs in all age groups (Figures 6A-F). No cellular aggregation or organized structures were observed at ED18 or 1 day of age, but small aggregations of CSF1Rtransgene $^{+}$cells were observed in 1-week-old chicks. Interestingly, at 1 day post-hatch CSF1R-transgene ${ }^{+}$cells begin to form a pattern and clustering can be observed in the vicinity of capillary formation (Figure 6B). The lymphoid aggregates are primarily located at the vicinity and bifurcation of capillaries (Figure 6C). These CSF1Rtransgene ${ }^{+}$cellular aggregates increase in size and number with age and are frequently observed at 2 and 4 weeks of age (Figures 6D and E). At 8 weeks of age, many of these aggregates have GCs, characterized by tightly packed aggregates of CSF1R-transgene ${ }^{+}$cells surrounded by a clear halo (Figure $6 \mathrm{~F}$ ).

To demonstrate the potential utility of MacReporter chickens in dissecting host-pathogen interactions, antigen-uptake and vaccine targeting, pilot studies were undertaken using fluorescently labelled beads and heatinactivated APEC-GFP. Figure 7 shows the deposition of intratracheally administered red fluorescent beads in the openings to the $\mathrm{SB}$, in the air sac, and uptake of fluorescent beads by respiratory epithelium and by MNPs (Figures 7A-D). We were also able to demonstrate colocalisation of APEC-GFP and lymphoid follicle in the BALT area and uptake in the parabronchus of APEC-GFP in CSF1R-transgene ${ }^{+}$cells (Figures 7F and G). Ongoing studies are examining the cell tropism of APEC strains representing dominant serogroups and cellular responses by RNA sequencing of sorted infected cells.

\section{Discussion}

The advantage of using MacReporter chickens is that the development of the lymphoid structures can be assessed ex vivo using whole mount imaging of the entire tissue without the need for tissue preparation and histology. Moreover, the entire trachea and lung can be imaged, lowering the risk of missing smaller focal structures and enabling to dissect specific areas of interest. By analyzing a number of developmental stages during chicken growth, we observed the presence and expansion of lymphoid aggregates consisting of CSF1R-transgene ${ }^{+}$cells in the respiratory tract from vaccinated and non-vaccinated animals.

For the first time the lymphoid aggregates in the whole avian lung were visualised via whole mount microscopy. This application allowed for the visualisation of numerous CSF1R-transgene ${ }^{+}$cellular aggregates in the vicinity of openings to the laterodorsal and mediodorsal SB. The presence of constitutive BALT has been described in chickens, rats and rabbits [7]. In humans, BALT can be found in childhood but regresses into adulthood. However, its constitutive presence is still controversial [38, 39]. A related BALT-like structure known as inducible BALT (iBALT), an ectopic lymphoid tissue, can be found upon inflammation or infection in both mice and humans and appears throughout the lung [39, 40]. In our study vaccinated and nonvaccinated animals reared under conventional conditions presented no differences in the presences of BALT structures albeit vaccinated animals may have more active immune system compared to unvaccinated animals. In chickens, ectopic lymphoid tissues appear in 

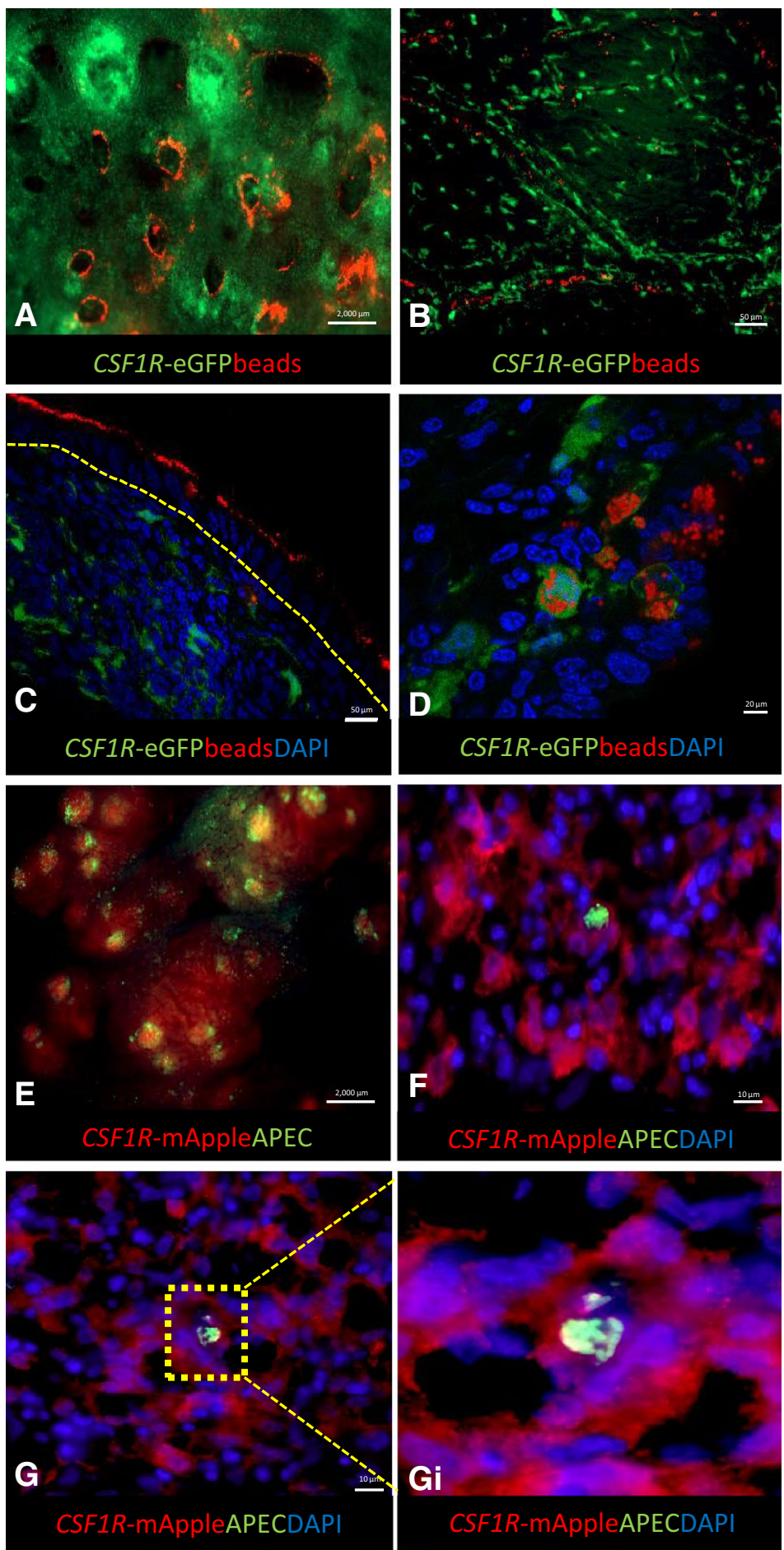

Figure 7 Applications of the CSF1R-transgenic birds to study the avian respiratory-associated immune responses. Intratracheal application of red carboxlylated fluorescence beads in a MacGreen reporter bird (A-D) and APEC-GFP in a MacRed reporter bird (E-F). Thirty mins post-intratracheal administration, beads $(1 \mu \mathrm{m})$ are deposited at the openings of the SB (A). At 3 h post administration, the beads are co-located with the capillaries of air sacs (B). Visualisation of binding and phagocytosis of particles in the lung demonstrated by binding of beads to the epithelial cells of the BALT (C; $0.1 \mu \mathrm{m}$ beads, thirty min post-administration,) and intracellular beads in CSF1R-eGFP ${ }^{+}$cells ( $\mathbf{D} ; 1 \mu \mathrm{m}$ beads, $3 \mathrm{~h}$ post-administration). An example of host-pathogen interactions is demonstrated in $\mathbf{E}-\mathbf{F}$. Thirty min after intra-tracheal administration, bacteria can be found bound to FAE of the lung (E) and APEC-GFP uptake by CSF1R-mApple ${ }^{+}$cells in the parabronchus can be visualized 1 day post-infection (F-G-Gi). The epithelial layer is indicated by yellow dashed line. 
the lung after infection with, for example, avian influenza virus (Vervelde and Reemers, unpublished observations). The development of the BALT in the chicken lung was progressive and consistent with those previously reported [11], with lymphoid follicles and the number of follicles associated with each opening of SB increasing in size and number with age. In contrast to previous studies, in the MacReporter birds we saw small aggregates were already present in 1-week-old chicks. The earlier detection might have been due the fact that animals were vaccinated via the drinking water 1 day post-hatch, but more likely because we could analyse the complete lung instead of histological sections only. Mature BALT structures with B and T cell areas and GCs were observed from 4 weeks of age onwards. Interestingly, lymphoid follicles were also present around the medioventral SB in some of the birds. These are the most cranial SB, and are composed of four large openings in the genus Gallus [8]. This is in contrast with previous literature [7], which only reports BALT in the vicinity of the most caudal SB (the laterodorsal and posterior $\mathrm{SB}$ ).

We examined the MNPs and epithelial cells of the BALT and parabronchi of the lung from 5 to 7 week old non-vaccinated birds reared under conventional conditions. Using immunofluorescence staining, the CSF1Rtransgene $^{+}$lymphoid aggregates observed via whole mount microscopy, were also present in non-vaccinated animals and were tightly packed GCs consisting of B cells, FDC and tingible body macrophages, distinguished based on their Bu-1 (chB6) and TIM4 staining and CSF1R-transgene ${ }^{+}$expression. The presence of multiple GCs in the BALT region of non-vaccinated animals is similar to earlier findings that SPF and conventionally reared birds had no difference in BALT development [7]. LAMP1 staining colocalised with CSF1R-transgene expression but was also found in cells lacking CSF1Rtransgene expression. These cells may represent phagocytic cells that express LAMP1 in their cytotoxic granules that do not express the transgene, such as natural killer cells [41] or express the transgene at low levels, such as granulocytes [26]. Respiratory MNPs in the parabronchi have been described previously with $\mathrm{CD}_{1} 1^{+}, \mathrm{KUL} 1^{+}$ and $\mathrm{DEC} 205^{+}$cells located in the interstitial tissue of the primary bronchus wall and $\mathrm{CD}_{1} 1^{+}$and $\mathrm{KULO}^{+}$ cells located in interatrial septa [17]. Although the present study did not distinguish between macrophages and DCs, the MacReporter chicken allow for the appreciation of the location and quantity of MNP in the BALT and parabronchi of unvaccinated healthy animals. We also observed the presence of $\mathrm{M}$ cells in the FAE overlaying the BALT. Previous reports have identified these cells by transmission electron microcopy in the turkey [11] and failed to identify them in chicken lung by SEM [7]. In our studies these cells were found to express the CSF1Rtransgene and lack jacalin binding in contrast to the IFE overlaying the BALT structure. This observations makes BALT-associated $\mathrm{M}$ cell identification and study more accessible. $M$ cells can mediate infection by bacteria [35, 42] and viruses [43] and may represent a route to infection in chickens as observed in mammals [35, 36].

In the lung parabronchi, pneumocytes in the interatrial septa were found to be positive for LAMP1 staining but lacked CSF1R-transgene expression. The LAMP1 staining in epithelial cells lining the atria suggests that these cells are able to phagocytose and process antigens. These lysosomal bodies in avian pneumocytes have been previously described [44] and the cells were classified as type II pneumocytes [45]. Besides being $\mathrm{LAMP}^{+}$, they also express the FDC marker CVI-ChNL-74.3 [46]. The limited number of highly mobile free residing macrophages in the lumen maybe correlated to the fact that the avian epithelium immediate to the respiratory surface is strongly phagocytic [45]. In addition to the airway, $M$ cells in the epithelium of the primary bronchus expressing CSF1R-transgene, these type II pneumocytes also express molecules in common with MNPs. Similarly, mouse, sheep, and human type II pneumocytes and MNPs express DC-LAMP/CD208 [47] and RAGE [48]. Small aggregates of $\mathrm{MHC} \mathrm{II}^{+}$cells are occasionally observed in the parabronchi indicating that, along with the BALT, the parabronchi play an important role in the immune response of the avian lung. Scattered $\mathrm{CD} 4^{+}$ and $C D 8 \alpha^{+}$cells are also present in the parabronchi and occasionally forming subepithelial aggregates of variable sizes. Perivascular clusters of B and T cells are observed, and in older birds occasionally have GCs (unpublished observations) [22]. Together with macrophages, $\mathrm{T}$ cell numbers increase rapidly after infection or vaccination with respiratory viruses or bacterial infections $[19,21$, $43,49]$. The combination of free residing macrophages, phagocytic epithelium, the numerous macrophages and DC in the underlying tissue and the fact that these cells can been mobilised rapidly after infection ensures an effective cellular defense system in the chicken lung.

The development of GCs in the trachea was observed using the MacReporter animals. From ED18 up to 8 weeks post-hatch, the accumulation of tightly packed areas with multiple follicles increased with age. Changes in MNP in the trachea have been reported after infection with e.g. IBV, E. coli $[19,49]$ and ITLV [50]. A similar pattern of lymphoid accumulation during development was also evident in the avian air sacs. Using electron microscopy, Bezuidenhout reported similar findings to this report where perivascular aggregation of leucocytes (macrophages, heterophils, lymphocytes, plasma cells, 
monocytes and mast cells) were observed in the air sacs [23]. The perivascular aggregation of CSF1R-transgene ${ }^{+}$ cells in the air sac could indicate that these cells play an important role in the induction of the local immune response as previously seen after infection with IBV and E. coli $[19,22]$. Our pilot studies using inert beads and inactivated APEC bacteria show the potential of the MacReporter birds to investigate the respiratory immune system during infection and provide the tools to better investigate host-pathogen interactions and vaccine targeting.

In summary, we demonstrated the potential of CSF1Rtransgenic MacReporter birds to visualize lymphoid tissue in the respiratory tract of birds of all ages using whole mount imaging and immunofluorescent staining. In all tissues, trachea, lung and air sac, the development was progressive, with the number and size of lymphoid follicles increasing with age. It should be noted that some animals were vaccinated via drinking water which may play a role in the early detection and abundance of follicles observed in this study. The expression of the transgene enabled us to visualize organized lymphoid tissue at an earlier age and especially at different locations than previously published. The results presented in this study will serve as a base for further functional characterization of MNP, macrophages and DC subpopulations in uptake processing and presentation of antigens to $\mathrm{T}$ and $B$ cells and the role of MNP in respiratory diseases such as E. coli, IBV and avian influenza.

\section{Additional files}

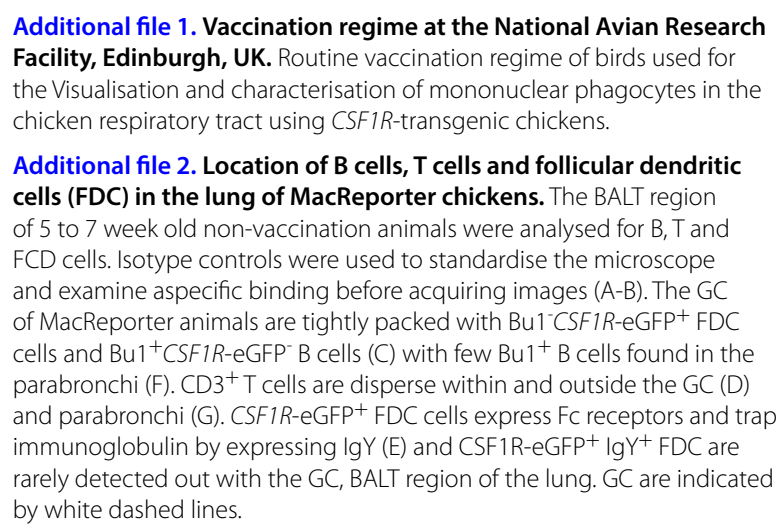

Additional file 2. Location of B cells, $T$ cells and follicular dendritic cells (FDC) in the lung of MacReporter chickens. The BALT region of 5 to 7 week old non-vaccination animals were analysed for B, T and FCD cells. Isotype controls were used to standardise the microscope and examine aspecific binding before acquiring images (A-B). The GC of MacReporter animals are tightly packed with Bu1-CSFIR-eGFP+ FDC cells and Bu1 ${ }^{+}$CSF1R-eGFP- $B$ cells (C) with few Bu1 ${ }^{+}$B cells found in the parabronchi (F). $\mathrm{CD}^{+} \mathrm{T}$ cells are disperse within and outside the GC (D) and parabronchi (G). CSF1R-eGFP ${ }^{+}$FDC cells express Fc receptors and trap immunoglobulin by expressing $\lg Y(E)$ and CSF1R-eGFP ${ }^{+} \lg Y^{+}$FDC are rarely detected out with the GC, BALT region of the lung. GC are indicated by white dashed lines.

\section{Abbreviations}

AIV: avian influenza virus; APC: antigen presenting cells; APEC: avian pathogenic Escherichia coli; BALT: bronchus associated lymphoid tissue; CSF1R: colony stimulating factor 1 receptor; DC: dendritic cell; ED: embryonic day of incubation; eGFP: enhanced green fluorescent protein; FAE: follicle associated epithelium; FDC: follicular dendritic cells; GALT: gut-associated lymphoid tissue; GC: germinal center; IBV: infectious bronchitis virus; IFE: interfollicular epithelium; LAMP1: Iysosomal-associated membrane protein 1; MNP: mononuclear phagocytes; PB: primary bronchus; PBS: phosphate buffered saline; SB: secondary bronchus.

\section{Competing interests}

The authors declare that they have no competing interests.

\section{Authors' contributions}

$\mathrm{KS}, \mathrm{TC}, \mathrm{MS}$ and LV made contributions to the design, acquisition and interpretation of the data and have drafted the manuscript. $A B$ assisted with the whole mount imaging. $A A, K B$, and DB have assisted with the animal experiments. All authors read and approved the final manuscript.

\section{Acknowledgements}

We would like to dedicate this paper to our colleague and friend Prof. Pete Kaiser. We want to thank the animal caretakers of the National Avian Research Facility for their help and supply of birds, Dr Tuanjun Hu and The Roslin Institute Toolbox for the development and production of chTIM4 antibody respectively, and The Roslin Bioimaging facility for training and advice. We would like to thank Drs. Prerna Vohra and Cosmin Chintoan-Uta for kindly providing the pFVP25.1 plasmid and assistance with the construction of the APEC-GFP strain and all collaborators for fruitful discussions.

\section{Ethics approval and consent to participate}

Animals were housed in premises licensed under a UK Home Office Establishment License (PEL 60/4604) in full compliance with the requirements of the Animals (Scientific Procedures) Act 1986. Breeding of transgenic chickens was carried out under the authority of Project License PPL 70/8940 and application of substances was conducted under PPL 70/7860 with the consent of The Roslin Institute Animal Welfare and Ethical Review Board.

\section{Funding}

This work was supported by the Biotechnology and Biological Sciences Research Council (BBSRC) as part of the joint NIFA-BBSRC Animal Health and Disease program (BB/M028208/1 and USDA-NIFA AFRI Grant No. 2015-6701523093), by BBSRC responsive mode funding (BB/M003094/1), and BBSRC funding via the ERA-NET Animal Health and Welfare (ANIHWA) initiative BB/ M028305/1. It was also supported by a BBSRC strategic investment at The Roslin Institute (BB/P013732/1 and BB/P013759/1). The funding sources had no involvement in the study design nor in the writing of the report and the decision to submit the article for publication.

\section{Publisher's Note}

Springer Nature remains neutral with regard to jurisdictional claims in published maps and institutional affiliations.

Received: 8 June 2018 Accepted: 24 September 2018

Published online: 10 October 2018

\section{References}

1. Jeurissen SHM, Vervelde L, Janse EM (1994) Structure and function of lymphoid tissues of the chicken. Poultry Sci Rev 5:183-207

2. Hogenkamp A, Isohadouten N, Reemers SSN, Romijn RA, Hemrika W, White MR, Tefsen B, Vervelde L, van Eijk M, Veldhuizen EJA, Haagsman HP (2008) Chicken lung lectin is a functional C-type lectin and inhibits haemagglutination by influenza A virus. Vet Microbiol 130:37-46

3. Cuperus T, van Dijk A, Dwars RM, Haagsman HP (2016) Localization and developmental expression of two chicken host defense peptides: cathelicidin-2 and avian $\beta$-defensin 9. Dev Comp Immunol 61:48-59

4. McLelland J (1989) Anatomy of the lungs and air sacs. In: King AS, McLelland J (eds) Form and function in birds, vol 4. Academic Press, Toronto

5. Reemers SS, van Haarlem DA, Koerkamp MJG, Vervelde L (2009) Differential gene-expression and host-response profiles against avian influenza virus within the chicken lung due to anatomy and airflow. J Gen Virol 90:2134-2146

6. Härtle S, Kaspers B (2014) The avian respiratory immune system. In: Schat KA, Kaspers B, Kaiser P (eds) Avian immunology, $2^{\text {nd }}$ edn. Academic Press, New York 
7. Fagerland J, Arp LH (1993) Structure and development of bronchusassociated lymphoid tissue in conventionally reared broiler chickens. Av Dis 37:10-18

8. Makanya AN, Djonov V (2008) Development and spatial organization of the air conduits in the lung of the domestic fowl, Gallus gallus variant domesticus. Microsc Res Tech 71:689-702

9. Bienenstock J, Befus D (1984) Gut- and bronchus-associated lymphoid tissue. Am J Anat 170:437-445

10. Bienenstock J, Johnston N, Perey DYE (1973) Bronchial lymphoid tissue. I. Morphologic characteristics. Lab Investig 28:686-692

11. Fagerland JA, Arp LH (1990) A morphologic study of bronchus-associated lymphoid tissue in turkeys. Am J Anat 189:24-34

12. Baharom F, Rankin G, Blomberg A, Smed-Sörensen A (2017) Human lung mononuclear phagocytes in health and disease. Front Immunol 8:499

13. Garbi N, Lambrecht BN (2017) Location, function, and ontogeny of pulmonary macrophages during the steady state. Pflugers Arch 469:561-572

14. Toth TE, Siegel PB (1986) Cellular defense of the avian respiratory tract: paucity of free-residing macrophages in the normal chicken. Av Dis 30:67-75

15. Jeurissen SHM, Janse EM, Kok GL, de Boer GF (1989) Distribution and function of non-lymphoid cells positive for monoclonal antibody CVIChNL-68.2 in healthy chickens and those infected with Marek's disease virus. Vet Immunol Immunopathol 22:123-133

16. Reese S, Dalamani G, Kaspers B (2006) The avian lung-associated immune system: a review. Vet Res 37:311-324

17. de Geus ED, Jansen CA, Vervelde L (2012) Uptake of particulate antigens in a nonmammalian lung: phenotypic and functional characterization of avian respiratory phagocytes using bacterial or viral antigens. J Immunol 188:4516-4526

18. Krunkosky M, García M, Beltran Garza LG, Karpuzoglu-Belgin E, Levin J, Williams RJ, Gogal RM Jr (2018) Seeding of the mucosal leukocytes in the HALT and trachea of White Leghorn chickens. J Immunoassay Immunochem 39:43-57

19. Matthijs MGR, Ariaans MP, Dwars RM, van Eck JHH, Bouma A, Stegeman $A$, Vervelde $L$ (2009) Course of infection and immune responses in the respiratory tract of IBV infected broilers after superinfection with E. coli. Vet Immunol Immunopathol 127:77-84

20. Reemers SS, Jansen C, Koerkamp MJ, van Haarlem D, van de Haar P, Degen WG, van Eden W, Vervelde L (2010) Reduced immune reaction prevents immunopathology after challenge with avian influenza virus: a transcriptomics analysis of adjuvanted vaccines. Vaccine 28:6351-6360

21. Wattrang E, Dalgaard TS, Norup LR, Kjærup RB, Lundén A, Juul-Madsen HR (2015) CD107a as a marker of activation in chicken cytotoxic T cells. J Immunol Methods 419:35-47

22. Dwars RM, Matthijs MG, Daemen AJ, van Eck JH, Vervelde L, Landman WJ (2009) Progression of lesions in the respiratory tract of broilers after single infection with Escherichia coli compared to superinfection with E. coli after infection with infectious bronchitis virus. Vet Immunol Immunopathol 127:65-76

23. Bezuidenhout AJ (2005) Light and electron microscopic study of the thoracic respiratory air sacs of the fowl. Anat Histol Embryol 34:185-191

24. Klika E, Scheuermann DW, De Groodt-Lasseel MHA, Bazantova I, Switka A (1996) Pulmonary macrophages in birds (Barn owl, Tyto tyto alba), domestic fowl (Gallus gallus f. domestica), quail (Coturnix coturnix), and pigeons (Columbia livia). Anat Rec 246:87-97

25. Cook RD, Vaillant C, King AS (1987) The structure and innervation of the saccopleural membrane of the domestic fowl, Gallus gallus: an ultrastructural and immunohistochemical study. J Anat 150:1-9

26. Balic A, Garcia-Morales C, Vervelde L, GilhooleyH H, Sherman A, Garceau V, Gutowska MW, Burt DW, Kaiser P, Hume DA, Sang HM (2014) Visualisation of chicken macrophages using transgenic reporter genes: insights into the development of the avian macrophage lineage. Development 141:3255-3265

27. Hu T, Wu Z, Bush SJ, Freem L, Vervelde L, Summers KM, Balic A, Hume DA, Kaiser P (2018) Characterisation of subpopulations of chicken mononuclear phagocytes that express TIM4 and the macrophage colony-stimulating factor receptor (CSF1R). bioRxiv 294504 https://doi. org/10.1101/294504

28. Trampel DW, Fletcher OJ (1980) Ring-stabilization technique for collection of avian air sacs. Am J Vet Res 41:1730-1734

29. Johnson TJ, Kariyawasam S, Wannemuehler Y, Mangiamele P, Johnson SJ, Doetkott C, Skyberg JA, Lynne AM, Johnson JR, Nolan LK (2007) The genome sequence of avian pathogenic Escherichia coli strain O1:K1:H7 shares strong similarities with human extraintestinal pathogenic E. coli genomes. J Bacteriol 189:3228-3236

30. Valdivia RH, Falkow S (1996) Bacterial genetics by flow cytometry: rapid isolation of Salmonella Typhimurium acid-inducible promoters by differential fluorescence induction. Mol Microbiol 22:367-378

31. Jeurissen SHM, Janse EM, Koch G, de Boer GF (1989) Postnatal development of mucosa-associated lymphoid tissues in chickens. Cell Tissue Res 258:119-124

32. Kroese FGM, Eikelenboom P, Van Rooijen N (1982) Electronmicroscopical and enzymehistochemical characterisation of immune complex trapping cells in the spleen of different vertebrate species. Dev Comp Immunol Suppl 2:69-74

33. Thunold S, Boyd R, Schauenstein K, Wick G (1982) Tissue localization of lymphocyte surface antigens and receptors for immunoglobulin G Fc and complement in the chicken. J Histochem Cytochem 30:201-206

34. Yasuda M, Taura Y, Yokomizo Y, Ekino S (1998) A comparative study of germinal center: fowls and mammals. Comp Immunol Microbiol Infect Dis 21:179-189

35. Nair VR, Franco LH, Zacharia VM, Khan HS, Stamm CE, You W, Marciano DK, Yagita H, Levine B, Shiloh MU (2016) Microfold cells actively translocate Mycobacterium tuberculosis to initiate infection. Cell Rep 16:1253-1258

36. Mabbott NA, Donaldson DS, Ohno H, Williams IR, Mahajan A (2013) Microfold (M) cells: important immunosurveillance posts in the intestinal epithelium. Muc Immunol 6:666-677

37. Smythe E, Ayscough KR (2006) Actin regulation in endocytosis. J Cell Sci 19:4589-4598

38. Debertin AS, Tscherni T, Schurmann A, Bajanowski T, Brinkmann B, Pabst $R$ (2006) Coincidence of different structures of mucosa-associated lymphoid tissue (MALT) in the respiratory tract of children: no indications for enhanced mucosal immunostimulation in sudden infant death syndrome (SIDS). Clin Exp Immunol 146:54-59

39. Randall TD (2010) Bronchus-associated lymphoid tissue (BALT) structure and function. Adv Immunol 107:187-241

40. Halle S, Dujardin HC, Bakocevic N, Fleige H, Danzer H, Willenzon S, Suezer Y, Hämmerling G, Garbi N, Sutter G, Worbs T, Forster R (2009) Induced bronchus-associated lymphoid tissue serves as a general priming site for T cells and is maintained by dendritic cells. J Exp Med 206:2593-2601

41. Jansen CA, van de Haar PM, van Haarlem D, van Kooten P, de Wit S, van Eden W, Viertlböck BC, Göbel TW, Vervelde L (2010) Identification of new populations of chicken natural killer (NK) cells. Dev Comp Immunol 34:759-767

42. Park HS, Francis KP, Yu J, Cleary PP (2003) Membranous cells in nasalassociated lymphoid tissue: a portal of entry for the respiratory mucosal pathogen group A streptococcus. J Immunol 171:2532-2537

43. Amerongen HM, Wilson GA, Fields BN, Neutra MR (1994) Proteolytic processing of reovirus is required for adherence to intestinal M cells. J Virol 68:8428-8432

44. Rebel JM, Peeters B, Fijten H, Post J, Cornelissen J, Vervelde L (2011) Highly pathogenic or low pathogenic avian influenza virus subtype H7N1 infection in chicken lungs: small differences in general acute responses. Vet Res $42: 10$

45. Scheuermann DW, Klika E, De Groodt-Lasseel MH, Bazantova I, Switka A (1997) An electron microscopic study of the parabronchial epithelium in the mature lung of four bird species. Anat Rec 249:213-225

46. de Geus E, Vervelde L (2013) Regulation of macrophage and dendritic cell function by pathogens and through immunomodulation in the avian mucosa. Dev Comp Immunol 41:41-351

47. Salaun B, de Saint-Vis B, Pacheco N, Pacheco Y, Riesler A, Isaac S, Leroux C, Clair-Moninot V, Pin JJ, Griffith J, Treilleux I, Goddard S, Davoust J, Kleijmeer M, Lebecque S (2004) CD208/dendritic cell-lysosomal associated 
membrane protein is a marker of normal and transformed type II pneumocytes. Am J Pathol 164:861-871

48. Katsuoka F, Kawakami Y, Arai T, Imuta H, Fujiwara M, Kanma H, Yamashita K (1997) Type Il alveolar epithelial cells in lung express receptor for advanced glycation end products (RAGE) gene. Biochem Biophys Res Commun 238:512-516

49. Horn F, Corrêa AM, Barbieri NL, Glodde S, Weyrauch KD, Kaspers B, Driemeier D, Ewers C, Wieler LH (2012) Infections with avian pathogenic and fecal Escherichia coli strains display similar lung histopathology and macrophage apoptosis. PLoS One 7:e41031

50. Abdul Cader MS, Amarasinghe A, Palomino-Tapia V, Ahmed-Hassan H, Bakhtawar K, Nagy E, Sharif S, Gomis S, Abdul-Careem MF (2018) In ovo CpG DNA delivery increases innate and adaptive immune cells in respiratory, gastrointestinal and immune systems post-hatch correlating with lower infectious laryngotracheitis virus infection. PLoS One 13:e0193964
Ready to submit your research? Choose BMC and benefit from:

- fast, convenient online submission

- thorough peer review by experienced researchers in your field

- rapid publication on acceptance

- support for research data, including large and complex data types

- gold Open Access which fosters wider collaboration and increased citations

- maximum visibility for your research: over $100 \mathrm{M}$ website views per year

At BMC, research is always in progress.

Learn more biomedcentral.com/submissions 